\title{
Chapter 6 \\ Developing and Assessing Next \\ Generation Community Policing Social Networks with THOR Methodology
}

\author{
George Leventakis and George Kokkinis
}

\section{Evolving Community Policing Models and the Impact of Social Network}

Community Policing (CP) is built on the belief that people deserve and have a right "to have a say" in policing in exchange for their participation and support (Kenney and McNamara 1999). CP is "The process of enabling the participation of citizens and communities in policing at their chosen level, ranging from providing information and reassurance, to empowering them to identify and implement solutions to local problems and influence strategic priorities and decisions" (Trottier 2015).

$\mathrm{CP}$ has become the paradigm of contemporary policing, evolving significantly over the past years (Johnston 2005; Tilley 2008). The CP evolution initiated with 1st Generation and "Innovation" (1979-1986) where early CP initiatives were referenced as "experiments" and "demonstration projects". From 1987 to 1994 CP continued evolving with the "Diffusion" phase and focused on drugs and fear of crime issues. The third generation known as "Institutionalization" continues from 1995 up to date with a broader scope of CP activities (Peak 2013).

Nowadays, a major difference to the classic CP studies of Whyte (1943), Gans (1982) and others is the emergence and spread of social media networks and mobile internet devices. Manning (2011) recognized the importance of technological components (modules) in a police-designed Social Network required to serve the police needs and support crime mapping and analysis. In addition, the rise of virtual communities and 'horizontal' online social networks have complicated the

G. Leventakis $(\bowtie) \cdot$ G. Kokkinis

Senior Advisor - European Projects, Center for Security Studies - KEMEA Hellenic Ministry of Interior - Public Order Sector, Athens, Greece

e-mail: gleventakis@kemea.gr; g.kokkinis@kemea-research.gr 
relationships with current police structures, which are organised geographically and hierarchically. Against the background of cultural and ethnic diversity the spread of new technologies injects an element of homogeneity and seemingly a level playing field. Therefore, the implementation of social media modules should be exploited by the police as a channel to establish interaction with community members.

\section{Next Generation Community Policing: The INSPEC ${ }^{2}$ T Solution}

INSPEC $^{2} \mathrm{~T}^{1}$ is a 3-year EU project started in May 2015, and has already mobilised and engaged a critical mass of users, across EU and overseas. With special emphasis on social media use in $\mathrm{CP}$, it consolidates and modernises bidirectional communication of stakeholders, using multi-level anonymity flags.

The projects' scope is to develop a sustainable framework for CP that effectively addresses and promotes seamless collaboration between the police and various communities. The fundamental goal of the project is to validate the research results and to identify good practices on cooperation between police and the society at a local, regional and national level. This concept includes incident reporting from both registered and anonymous community members using a properly designed social network for CP. The reports are processed online in a system made from intelligence components, which supports bidirectional and personalized communications, allow the engagement of community members to provide additional information and to enhance the use of available police resources. The concept described above is shown in Figs. 6.1 and 6.2.

\section{INSPEC ${ }^{2}$ T Solution Modules}

A modern CP solution should possess intelligence capabilities and its architecture has to be modular and based on open standard interfaces. This means that existing analysis modules and databases will be utilized and will be part of the advanced $\mathrm{CP}$ ecosystem. The INSPEC ${ }^{2} \mathrm{~T}$ advanced $\mathrm{CP}$ solution includes reporting tools, awareness raising \& educational gaming apps as well as intelligent command \& control modules.

Mobile Applications and Public Portal Two different incident reporting methods are supported. Citizens can either submit reports to the Public Portal using a computer or smartphone (without the installation of any application), or by installing the INSPEC ${ }^{2} \mathrm{~T}$ mobile application on their smartphones/tablets. An extended, in

\footnotetext{
${ }^{1}$ http://cordis.europa.eu/project/rcn/194895_en.html
} 


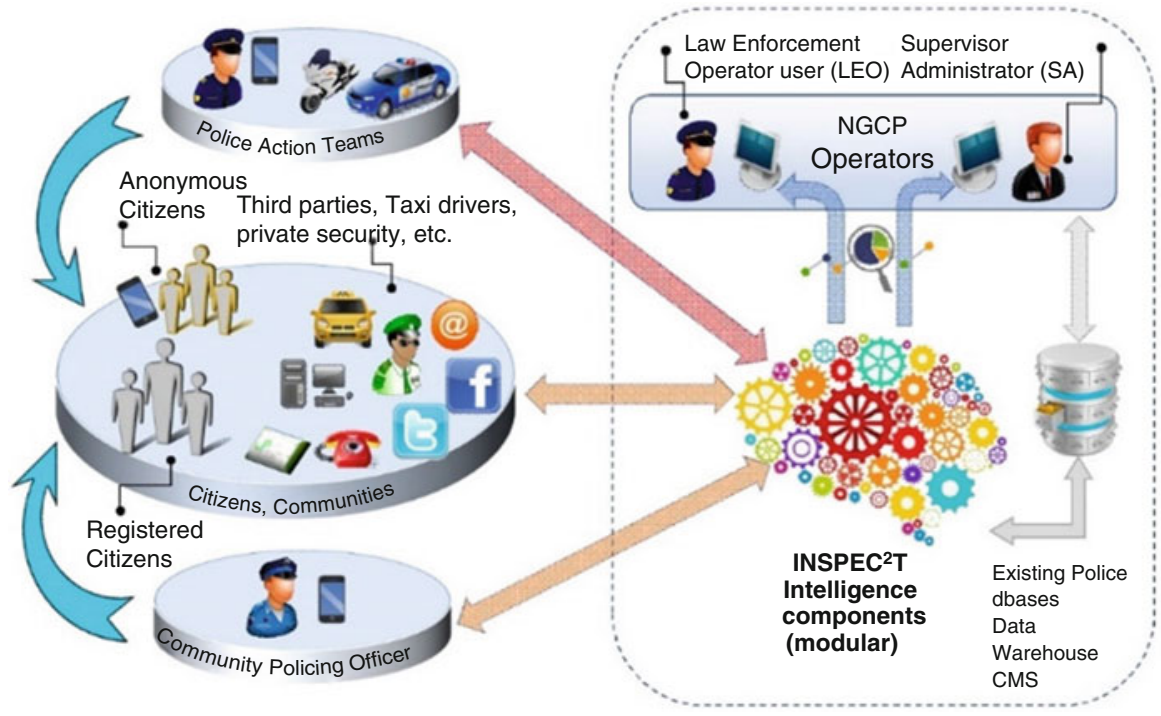

Fig. 6.1 The INSPEC ${ }^{2} \mathrm{~T}$ concept

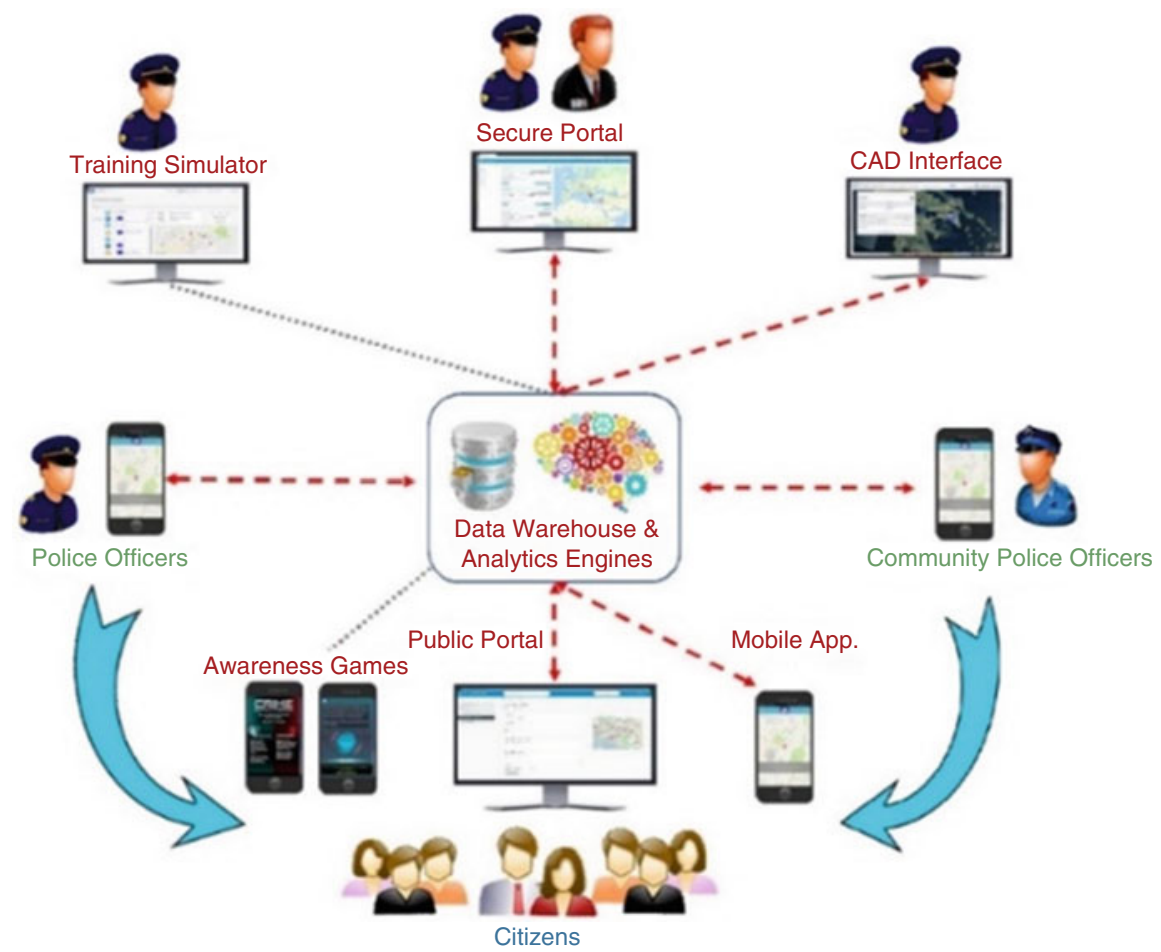

Fig. 6.2 The INSPEC ${ }^{2} \mathrm{~T}$ solution components 
terms of functionalities, version of the mobile application is available to $\mathrm{CP}$ officers for managing the reports and interact further with the system and its operators. Apart of the Mobile Applications and the Public Portal, an awareness game is also available. The gaming module, Resource Force ${ }^{2}$ aims to raise awareness about the citizens' contribution-value to $\mathrm{CP}$.

Geospatial Complex Event Processing (GCEP) This module addresses the challenge of processing huge amounts of data generated by either registered or anonymous users with embedded geolocation information. The submitted datasets are processed and analysed in a structural manner to provide meaningful information.

Multimedia Analytics (MMA) module is capable of extracting semantic information from a wide range of multimedia data sources like text, images, audio streams and videos. The quality assurance of the MMA module allows pre-processing and discarding of low quality data. The valid data are further analysed to produce speech transcription, detect acoustic events, allow person/face detection and reidentification and perform other multimedia correlations.

Business Intelligence Analytics (BIA) is a module to: (i) compute metrics for the activity and engagement of both citizens and police from all CP communication channels (e.g. community forums, social media accounts, etc.), (ii) implement sentiment analysis for the messages exchanged in the above-named channels, (iii) build a rating based user profile, by computing each user's activity within the advanced CP - Social Network, which typifies how active the user is and if they are contributing helpful information to the system or if they are malicious. It has to be noted, however, that the rating essentially concerns the information provided by the user rather than the users themselves.

Case Based Reasoning (CBR) module consists, by design, of two different submodules. The first one is composed of rules that the user should adjust or modify to make use of expert knowledge. The second submodule is equipped with a knowledge base to enable the inference of new rules and actions based on previous knowledge. In essence, the CBR module implements a way to measure similarity between concepts and relations of a prevailing ontology.

Data Processing Ageing (DPA) has to be configured according to the corresponding regulatory frameworks. Records may only be stored following a legitimate reason and massive storage of preventive data is not allowed. Record lifetime and criteria for deletion have to be determined in accordance to Data Protection legislation. The renewal of an item's date of expiration is possible and needs to be initiated from a user with the appropriate access rights.

Data Warehouse (DWH) integrates data from multiple heterogeneous sources and in different formats to support analytical reporting, structured and/or ad hoc queries

\footnotetext{
${ }^{2}$ https://play.google.com/store/apps/details?id=com.playgen.ResourceForce
} 
and decision making. DWH is an architectural model designed to support the flow of data from operational modules to decision support systems. The large amounts of heterogeneous data provided by citizens and communities over time are arranged into abstracted subject areas with time-variant versions of the same records, with an appropriate level of data grain or detail to make it useful for the intelligent modules described above to retrieve and analyse them.

Secure Portal (SP) The intelligence sub-modules mentioned above, (GCEP, MMA, BIA, CBR, DPA, and DWH) are all interfaced to the SP which provide operators with an advanced operational picture. The Law Enforcement Operator (LEO) and the INSPEC ${ }^{2} \mathrm{~T}$ Supervisor Administrator are in control of all CP submitted reports and, by utilising the intelligent processing capabilities of the advanced CP system, they manage all the reported incidents to extract useful and actionable information.

Training Simulator This module offers realistic in-situ simulations to allow the system administrators and Secure Portal operators to get familiarized with the platform, experience the potential impact of their decisions, interact in a safe environment, analyse their approach, facilitate peer assessment and benchmark so as to enable self-reflection and improvement. Moreover, the inclusion of courses with focus on privacy, data protection and how the system administrators should comply with ethical \& legal and societal requirements are mandatory items included in the advanced offered $\mathrm{CP}$ training program.

\section{Next Generation CP (NGCP) Functions Associated with Use Cases}

A Use Case $^{3}$ is a list of actions, typically defining the interactions between an actor and a system, to achieve an outcome. They document step by step instructions how to test the built-in functionality and demonstrate specific features and functionalities of a Next Generation Community Policing - Social Network (NGCP-SN). The use case categories outline the interactions between members of a NGCP-SN first among themselves, and then with other (existing) social networks and finally describe the collaboration between community members and police officers. The Use Case categories include: (i) Interaction with NGCP-SN; (ii) Communities; (iii) Incident Reporting and Management; (iv) Interaction with other SN's; (v) Backend Intelligence; (vi) Rules and Supporting Actions. The above classification is illustrated in Fig. 6.3. Next are briefly described the above six use case categories.

\footnotetext{
${ }^{3}$ https://www.ibm.com/support/knowledgecenter/en/SSWSR9_11.0.0/com.ibm.pim.dev.doc/pim_ tsk_arc_definingusecases.html
} 


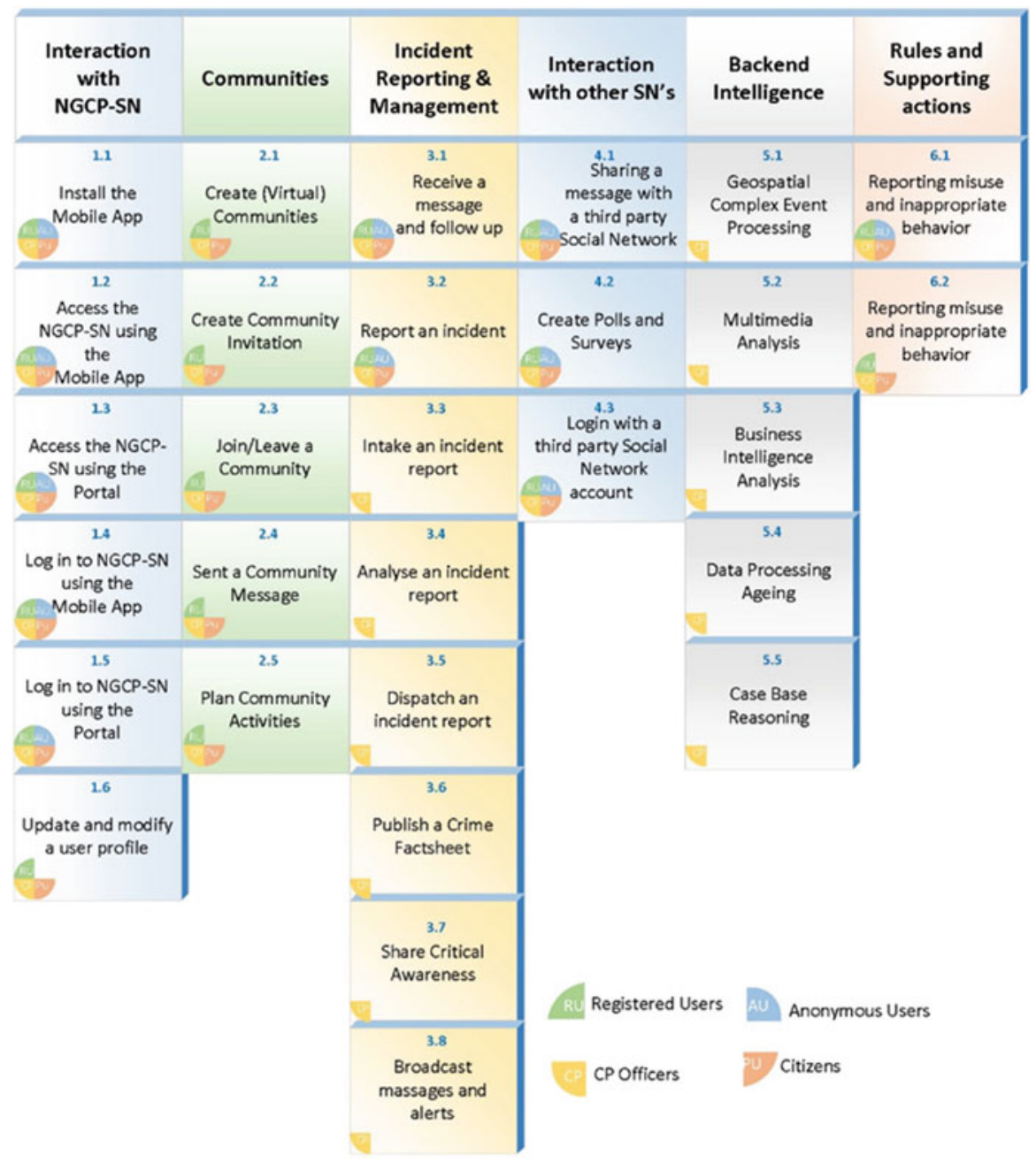

Fig. 6.3 Use cases for a NGCP - SN

\section{Interaction with NGCP-SN}

There are three different types of users supported in the INSPEC ${ }^{2} \mathrm{~T}$ solution. These are citizens (registered and/or anonymous) who wish to interact with the NGCP-SN and users with elevated access rights like CP officers, neighbourhood watch group representatives and municipality personnel. The citizens are offered the following two options: a) interact with the system (two-way communications) by providing their contact details, and b) receive only alerts and notification (oneway communication) if they choose to remain anonymous. Both registered and 
anonymous users should be allowed to access a NGCP-SN and should be offered the same rights for crime reporting and receive information about $\mathrm{CP}$ activities, police reports, alerts, etc. A registered user is also allowed to provide information anonymously.

Users who wish to engage with the INSPEC ${ }^{2} \mathrm{~T}$ solution and interact with the system using their mobile device(s), should download the Mobile App ${ }^{4}$ from their mobile applications store. The participants should be able to access the system also from the public portal using the browser in their mobile device. The users should be able to access the system either as registered and/or anonymous users.

\section{Communities}

The INSPEC ${ }^{2} \mathrm{~T}$ users should be able to form closed groups (communities) to discuss their safety and security needs and various topics of $\mathrm{CP}$ interest. There are two distinct categories of communities: Physical, where users are living in the same area will use the forum to exchange their views about crime / security in their neighbourhood or plan certain physically team activities; Virtual, where users with common interests (e.g. a merchant association) will come together to exchange ideas from their professional point of view. Following the creation of a community, it's members should send invitation to other users to join in. The created communities can also be announced in other SN's.

The community members should be able to post messages to other member(s) (one to one and one to many communication), or post messages to communities (one to all communications). The communication exchange can take place either publicly (message can be seen by other users at a later time) or privately within a group. Also, a group of LEAs assigned with CP duties should be reached either privately or publicly.

\section{Incident Reporting and Management}

Both registered and anonymous participants are able to receive messages either at their smartphones / tablets where the mob app is installed, or at their inboxes in the public portal. The messages might concern the announcement of a new event, a planned activity, an invitation to join a community, an alert or notification about an ongoing action and so on. Members of the NGCP-SN (citizens and CP officers) are able to create reports about an incident. The reporting can take place via the Mobile App or at the public portal and might concern an incident as it evolves or users might report a past event. The reportees at any time can provide additional information or

\footnotetext{
${ }^{4}$ https://play.google.com/store/apps/details?id=com.aditess.inspect2tCitizens
} 
clarification or even proceed with report deletion. The submitted report is directed to the police back end office where it is recorded and registered in the incidents database. The reported incident then becomes available to all backend subsystem for further processing.

Following the intake of the incident report the NGCP operator will use the back office built in intelligence to analyse the submitted reports and may share actionable information with the participants (both police officials and community members when required). The actionable information is stored in the system. The Secure Portal operator, who is a trained police officer, based on the reported information and the recommendations of police analysts, may decide if there is need to involve $\mathrm{CP}$ officers/police forces from the proximate to incident locations or asked citizens to provide additional information. While an incident is being dispatched to a $\mathrm{CP}$ officer, the system administrator after consulting his superiors and based on the urgency of the event, they might proceed with broadcasting an alert to all users of the NGCP-SN. Police intelligence analysts and other police officials can use the INSPEC ${ }^{2} \mathrm{~T}$ information to publish crime factsheets in order to create critical awareness among their network members. The users should receive notification after sending or sharing/information to police.

\section{Interaction with Other Social Networks}

To expand networking the NGCP-SN members should be able to share messages with other social media networks using either the public portal or the Mobile App. The messages can originate from an INSPEC $^{2} \mathrm{~T}$ user or a police official channel e.g. issue an Amber alert for a missing child and multicast the alert to NGCP-SN and other SM networks. The importance of interworking with existing social networks is explained with reference to recent developments ${ }^{5,6}$ in Manchester Arena and London Bridge. The police used Twitter to channel news as they were unfolded and eliminate speculation, rumours and fake news. This highlights the need of interaction with external social networks and necessitates police vigorousness to provide regularly updates, directions and eliminate malicious reporting.

Alike existing Social Network practices, INSPEC ${ }^{2} \mathrm{~T}$ users should be offered the option to take part in online surveys aiming to get responses from selected groups. Police Officials can create small surveys or simple polls and release them to selected group of participants to (i) extract specific information,(ii) have them rate their security needs and (iii) asked them what type of police information is required regarding different safety issues. If the survey initiator is aiming to expand the number of respondees then the survey or polls may well be shared using third party social networking platforms.

\footnotetext{
${ }^{5}$ http://www.bbc.com/news/uk-england-manchester-40007886

${ }^{6} \mathrm{http} / / / \mathrm{www} . b b c . c o m /$ news/uk-40013040
} 


\section{Back End Intelligence}

INSPEC $^{2} \mathrm{~T}$ is developed around a modular and open system $\operatorname{architecture}^{7}$ which promotes interconnections with existing modules and ensures information is not lost even in the event of some modules failed to function. The NGCP operator is offered the maximum information in real-time at each stage of processing and controls the information to be published. Additionally, the operator has access to offline information, for investigating incidents "a posteriori", perform data correlation, issue reports and build expert knowledge, for future alertness and CP actions. Multimedia event data and signals are processed fast, while authenticating, classifying and ranking sources. As such the system will try to drop pseudo evidence and "decoy" attempts. The system also utilises GIS information and multimedia content. The reported incidents enriched by multimedia essence, will be processed by the INSPEC ${ }^{2} \mathrm{~T}$ Parallel Processing modules. Analytics are applied, both to multimedia (video, images, speech) and web sources and an ontology is built and maintained.

\section{Rules and Supporting Actions}

To control possible violations and abuse within the NGCP-SN all users and administrators should follow an agreed code of conduct and terms of use. In the unlikely event that inappropriate behaviour is exercised by certain members, the affected users can alert the Community or the system Administrator and request immediate attention. Reporting of participants or community members that exercise harassment, exchange posts which contain abusive content or flag communities who use the system for other purposes for which it is not intended and indicate of inappropriate planned activities should be encouraged and promoted within a NGCP-SN. In addition, ethical, legal, societal and applicable data protection and privacy guidelines should complete the NGCP-SN terms and conditions.

\section{INSPEC $^{2}$ T Pilot Evaluation}

The first working INSPEC ${ }^{2} \mathrm{~T}$ version undertook trials in Belfast, in April 2017. CP Officers from Police Service Northern Ireland in cooperation with fellow Officers from Lancashire Constabulary participated, along with residents from the Holyland community and members of the Ulster University in the CP scenarios execution. The second pilot and a proof of concept demo to SAG and EEG committees took

\footnotetext{
${ }^{7}$ https://pdfs.semanticscholar.org/0bde/e147a7a3f04584424f5e32a54f65299a36ea.pdf
} 
place in Egkomi, Cyprus in May 2017. Also, in Cyprus, the consortium conducted a series of small scale pilots and solution demonstrations with engaged municipalities and LEAs. The third pilot took place in Valencia, Spain in May 2017. Further to the Valencia local police and local community involvement, there were representatives from San Sebastian Police and Guardia Civil.

\section{NGCP Evaluation Framework}

Following the development of the INSPEC ${ }^{2} \mathrm{~T}$ solution, an assessment framework was needed to verify whether the implemented functionalities satisfy the end user requirements. The THOR concept, which was developed by $\mathrm{CAMINO}^{8}$ project was adapted and used for the assessment of the INSPEC $^{2} \mathrm{~T}$ solution. The delivered solution was analysed in four dimensions as follows:

Technical Assess if the implemented solutions will assist the uptake of the NGCP$\mathrm{SN}$, and will provide the intelligence mechanisms required to analyse efficiently the user supplied information.

Human Evaluate how a series of human factors, behavioural aspects, privacy issues, ethical, societal and raising $\mathrm{CP}$ awareness activities will influence $\mathrm{CP}$ practices and more safe and secure communities.

Organisational Examine if the proposed processes, policies and procedures will enhance the cooperation between Communities and LEAs and if the project will result to better $\mathrm{CP}$.

Regulatory Inspect the project for adherence to law, standards, data protection and legal framework at national and EU level.

Each one of the THOR dimensions is divided into several areas of interest based on the assessment needs identified in the previous section. Following the execution of three pilots the feedback provided and results achieved were used to identify gaps and challenges that need to be overcome. The interaction of the THOR dimensions for the identified participant/user categories for the Use Case groups is shown in Fig. 6.4.

The succeeding sections outlines how each one of the THOR dimensions constitutes a CP verification framework and how each one of the use cases are mapped under a specific dimension to provide the assessment criteria and verify whether the stakeholder requirements have been addressed and to what extent.

\footnotetext{
${ }^{8}$ http://cordis.europa.eu/project/rcn/185485_en.html
} 


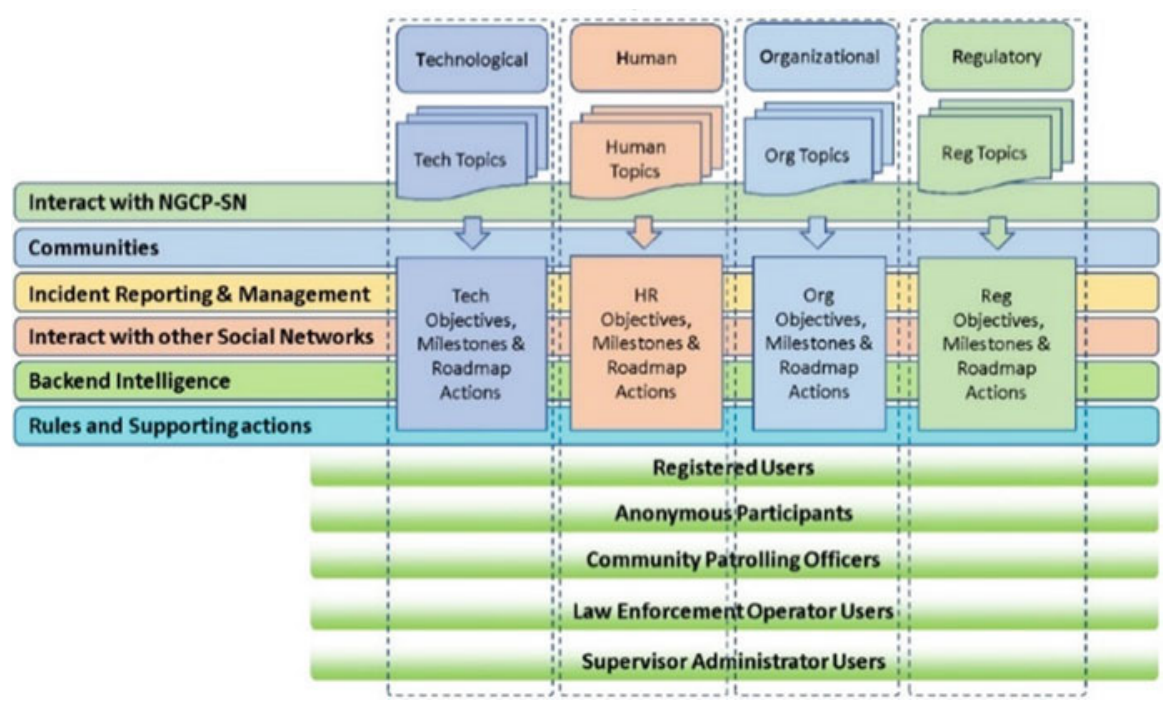

Fig. 6.4 THOR model applied to INSPEC ${ }^{2} \mathrm{~T}$ system

\section{Technology}

The improvements recorded by adopting technology offerings and included them in current $\mathrm{CP}$ practices is underlying the importance to understand which technology solutions will introduce additional value. Introducing IT to police operation is a complex and demanding task. Custers (2012) claims "it is not clear which technologies are more usable and effective in the context of a police organization". INSPEC $^{2} \mathrm{~T}$ offers LEAs a variety of technology innovative tools like applications for mobile devices, online presence, crime and multimedia analytic software (CBR, GCEP, MMA), information sharing (Public Portal and DWH) to be explored and assessed for their impact.

\section{Human}

One of the most fundamental aspects of improving CP is to empower the communities to prevent crime or the problems that lead to it. Establishing and maintaining mutual trust is therefore the central goal of $\mathrm{CP}$, as it allows wide law enforcement access to valuable community information leading potentially to the prevention and resolution of crimes (Docobo 2005). The citizens need to be aware of their own role and responsibilities and should proactively respond to indications of crime and disorder in their communities. In the INSPEC ${ }^{2} \mathrm{~T}$ ecosystem citizens are encourage to from and participate in communities while the project partners will assess human behaviour as a mean of collaboration, information exchange, awareness, efficacy and community building. 


\section{Organisational}

The first component of successful CP initiatives involves transformational changes in the organizational structure and operation of LEAs (Bureau of Justice Assistance 1994). The organisation changes proposed were evaluated using the "Three E's" efficiency, effectiveness, and enabling. (U.S. Department of Justice, Office of Community Oriented Policing Services 2017) Briefly, efficiency means getting a task done with a minimum expenditure of time and effort; effectiveness, is doing a better job to produce an intended or expected result, and finally, technologies will enable LEAs to do something they could not do before. CP is an information-intensive task/process, and technology plays a central role in helping to provide ready access to quality information. Accurate and timely information makes problem-solving efforts more effective and ensures that officers are informed about the crime and community conditions of their beat (Karp and Clear 2000). Therefore, two-way communications, online reports, discussion forums, and feedback using interactive applications is promoting engagement and increasing transparency.

\section{Regulatory}

The INSPEC ${ }^{2} \mathrm{~T}$ system aims to combine the principles of $\mathrm{CP}$ with the affordances of new technologies. Both the actual and the potential utilisation of the resulting tools have to be compliant with the legal frameworks so that they can be correctly implemented in participating countries. Moreover, taking into account the effects of EU directives ${ }^{9,10}$ and legal trends across the European Union may facilitate the exportation and application of the findings to countries that are not currently participating in the development of the INSPEC ${ }^{2} \mathrm{~T}$ system. ${ }^{11}$ In order to offer a broad picture of normative debates, established regulations, other relevant documents such as agreements, recommendations and guidelines which garnered public attention and might influence future regulations or foster best practices were considered. The resulted evaluation framework used to assess the INSPEC ${ }^{2} \mathrm{~T}$ solution is depicted in Fig. 6.5. Following the completion of first three pilots and the execution of a small-scale pilot in the SAG and EEG workshop the consortium received end user feedback and recommendations. These in conjunction with the provided end user requirements will shape and adjust the development of the solution prior the phase2 pilots, scheduled to take place between October and December 2017. The key outcomes of the stakeholder input are summarised hereafter.

\footnotetext{
${ }^{9} \mathrm{http} / / /$ eur-lex.europa.eu/legal-content/EN/TXT/?uri=CELEX\%3A32016L0680 (protection of natural persons with regard to the processing of personal data by competent authorities).

${ }^{10} \mathrm{http} / / /$ eur-lex.europa.eu/eli/reg/2016/679/oj (protection of natural persons with regard to the processing of personal data and on the free movement of such data).

${ }^{11}$ D2.2 Legal and Ethical dimensions of INSPEC2T System available online at: http://inspec2tproject.eu/en/public-deliverables.
} 


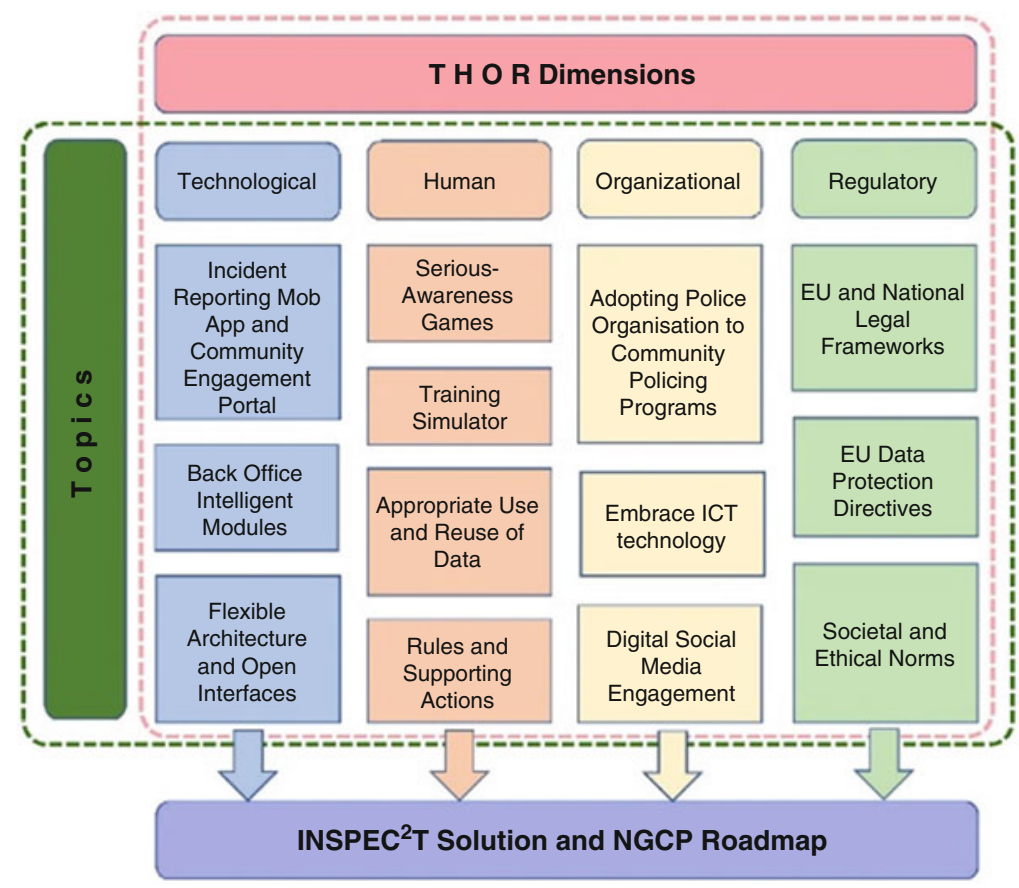

Fig. 6.5 THOR evaluation framework for INSPEC ${ }^{2} \mathrm{~T}$ assessment

\section{Interim Evaluation Findings}

Using a structured questionnaire, the INSPEC ${ }^{2} \mathrm{~T}$ members requested from the SAG and EEG committees to provide their feedback and guide the consortium endeavours to shape and finalise the solution to be tested in the phase- 2 pilots. Consenting the incident reporting using the mobile application, $93 \%$ of the experts indicated that it is offering the greatest potential to improve CP. Similarly, $71 \%$ prompted that the application for LEAs is a great asset for CP officers in the field. For the public portal $(50 \%)$ valued its use and ranked it top together with the mobile applications as a component that should be improvement to assist community building and empower citizens participation in $\mathrm{CP}$ tasks.

The collection of the "back office" components, (MMA, GCEP, BI, CBR, and $\mathrm{DWH}$ ) provides the intelligence to $\mathrm{INSPEC}^{2} \mathrm{~T}$ system to correlate, group and analyse the incoming reports and assists the Secure Portal operators to manage more effectively the reported incidents. The independent advisors indicated that cutting edge police command and control centers are already using a number of intelligence subsystems. Therefore, their adaptation to support CP operations is well perceived. The CAD interface supports legacy incident reporting systems; it is the gateway which feeds CP related reports that reach the call center into the INSPEC ${ }^{2} \mathrm{~T}$ system and supplies the required information to its operators with the location of police resources. 
All experts insisted in using open standards interfaces, as it makes sense to interconnect the demonstrated system with existing police systems like suspect databases and enhanced its functionalities. It is acknowledged that incident reporting if processes intelligently is a valuable intelligence source. Therefore, multimedia enriched content who is embedded in citizens' reports should be treated as a valuable information source. Kelling and Bratton (2006) specified that "Intelligence-led policing is crime fighting that is guided by effective intelligence gathering and analysis". Therefore, an intelligent CP system should be capable to supply and feed the existing police operational systems and if needed should have the capacity to provide facial recognition or offer acoustic event detection and alert its operators.

Lastly, the open interfaces can be utilised to forward incidents to other authorities, like the municipalities, or environmental agencies and forward reports (information) related to their scope which is reported by citizens using a CP system. After the pilot debriefing sessions with community representatives, the findings of the INSPEC $^{2} \mathrm{~T}$ public survey, ${ }^{12}$ where confirmed as citizens indicated that using the mobile application will result to more frequent reporting.

INSPEC $^{2} \mathrm{~T}$ developed an awareness raising game for citizens developed for iOS and Android devices. Using a gamification approach, the citizens were encouraged to collaborate with the police for the benefit of their communities. Through this game, the citizens realised that police resources are not infinite and as such their cooperation with police in a number of incidents will result better $\mathrm{CP}$ results. The INSPEC ${ }^{2} T$ 's training simulator is a scenario driven tool that simulates the submission of citizen reports and trains police operators to the functionality of the platform. The option to train $\mathrm{CP}$ system operators received positive feedback and it is a mandatory prerequisite for police organisations to offer customised to their needs and operational training to their CP Officers. The community and police relations in a social media like ecosystem will be studied in the phase-2 pilots. Therefore, the rules and the supporting actions required to prevent inappropriate behaviour and promote community and police interactions will be tested between October and November 2017.

The topics of EU's legal framework and data protection directives were discussed in all pilot's debriefing sessions and debated on a roundtable with SAG and EEG members. All experts agreed that the topic of data protection is well defined in EU directive 2016/680 which is designed to be consistent with the General Data Protection Regulation. Although Police officers as a competent authority, can process personal data for the "prevention of threats to public security" (Article 1), it is not clear at the moment which are the governing rules for use and reuse of data for $\mathrm{CP}$ purposes. The fact that the INSEPC ${ }^{2} \mathrm{~T}$ solution implemented adaptable safeguards for data ageing and the archiving and retention of submitted records is well perceived.

\footnotetext{
${ }^{12}$ D1.2 - "End User Requirements - 1st SAG Report" available online at: http://inspec2t-project. eu/en/public-deliverables
} 
Likewise, the police adaptation to $\mathrm{CP}$ programs, the inclusion of modern ICT solutions to everyday policing tasks, and the police strategy towards digital and social media are topics outside the influenced sphere of INSPEC $^{2} \mathrm{~T}$ or other similar initiatives. To this extent, the consortium studied and analysed a number of indicators which considered essential in implementing CP. Fostering and developing police-community relations requires active engagement from the police organisation, individual officers and community representatives. A CP maturity model is currently being developed for the purpose of producing $\mathrm{CP}$ policy recommendations to EU.

\section{Conclusions}

Following the completion of the first three pilots, the consortium received requests for further testing the INSPEC ${ }^{2} \mathrm{~T}$ solution in a variety of different $\mathrm{CP}$ contexts. In a number of debriefing sessions with Police officers and community members the following functionalities were valued: (1) The way of reporting incidents and contacting the police using the Mobile App. (2) Feedback about the status of submitted reports (3) Organising of information and management of incidents; (4) Reporting using multimedia content; and (5) Visualization on a map of the location of an incident. Overall incident reporting and communications via a social media network is well perceived by both Police and communities.

In sort INSPEC ${ }^{2} \mathrm{~T}$ was considered a substantial transition in the way of working for both the police and the citizen and to their mutual relationship, while Police officers were positive about the technical capabilities of the solution. The consortium members are currently working to incorporate the provided suggestion into the platform, evolve existing features and add new functionalities prior to the second testing phase. The final system tests will take place in Groningen (the Netherlands) between September and December 2017 (for 9 weeks) and in Preston (England) in November 2017.

Acknowledgment The work presented in this paper received funding from the European Commission, under the "H2020-FCT-2014 Ethical/Societal Dimension Topic 2: Enhancing cooperation between law enforcement agencies and citizens - Community policing" call entitled INSPEC ${ }^{2} \mathrm{~T}$ (Inspiring CitizeNS Participation for Enhanced Community PoliCing AcTions) under grant agreement number 653749 .

\section{References}

Bureau of Justice Assistance. (1994). Understanding community policing, a framework for action. Washington, DC: U.S. Department of Justice.

Custers, B. (2012). Technology in policing: Experiences, obstacles and police needs. Computer Law \& Security Review, 28, 62-68. 
Docobo, J. (2005). Community Policing as the Primary Prevention Strategy for Homeland Security at the Local Law Enforcement Level. Homeland Security Affairs, 1, Article 4.

Gans, H. (1982). The urban villagers: Group and class in the life of Italian-Americans. New York: Free Press (Macmillan Co., Inc.).

Johnston, L. (2005). From 'community' to 'neighbourhood' policing: Police community support officers and the 'police extended family' in London. Journal of Community \& Applied Social Psychology, 15, 241-254.

Karp, D., \& Clear, T. (2000). Community justice - A conceptual framework. Criminal Justice, 2, 323-368.

Kelling, G., \& Bratton, W. (2006). Policing terrorism, civic bulletin 43. New York: Manhattan Institute for Policy Research.

Kenney, D., \& McNamara, R. (1999). Police and policing: Contemporary issues. London: Greenwood Publishing Group.

Manning, P. K. (2011). Crime mapping, information technology, and the rationality of crime control. NYU Press.

Peak, K. (2013). Encyclopedia of community policing and problem solving. University of Nevada, Reno: SAGE Publications.

Tilley, N. (2008). Modern approaches to policing: Community, problem-oriented and intelligenceled. In Handbook of policing. Routledge Handbooks Online.

Trottier, D. (2015). Open source intelligence, social media and law enforcement: Visions, constraints and critiques. European Journal of Cultural Studies, 18, 530-547.

U.S. Department of Justice, Office of Community Oriented Policing Services. (2017). [Online]. Available at: https://ric-zai-inc.com/Publications/cops-p157-pub.pdf

Whyte, W. (1943). Street corner society: The social structure of an Italian slum. Chicago: Chicago University Press.

Open Access This chapter is licensed under the terms of the Creative Commons Attribution 4.0 International License (http://creativecommons.org/licenses/by/4.0/), which permits use, sharing, adaptation, distribution and reproduction in any medium or format, as long as you give appropriate credit to the original author(s) and the source, provide a link to the Creative Commons license and indicate if changes were made.

The images or other third party material in this chapter are included in the chapter's Creative Commons license, unless indicated otherwise in a credit line to the material. If material is not included in the chapter's Creative Commons license and your intended use is not permitted by statutory regulation or exceeds the permitted use, you will need to obtain permission directly from the copyright holder. 